\title{
THE MAINTENANCE OF THE LETHAL GENE CURLY IN EXPERIMENTAL POPULATIONS OF DROSOPHILA MELANOGASTER
}

\author{
CLAUDINE PETIT AND DANIELLE NOUAUD \\ Laboratoire de Génétique des Populations, Universite Paris 7-Tour 42, 2, place Jussieu \\ 75005 Paris
}

Received 21.xii.83

\section{SUMMARY}

\begin{abstract}
An analysis of the fitness components responsible for the maintenance of the lethal gene Curly in Drosophila melanogaster was made. The two competing strains, Curly and vestigal were the same except for chromosome 2 . Three populations were studied for more than twenty generations and all attained similar equilibrium frequencies. The fitness components were measured. Equilibrium was maintained by a balance between $C y$ homozygote lethality, disadvantage of $\mathrm{Cy}$ heterozygotes in viability, heterosis in fecundity, and a frequent dependent heterosis for sexual selection. The role that each major component of fitness is expected to play in experimental populations, as the gene frequency changes, is discussed.
\end{abstract}

\section{INTRODUCTION}

Fitness is the result of complex and antagonistic forces. The first analysis, both in terms of a mathematical model and in terms of experimental measurement, was made in the early forties by Teissier (1942 $a$ and $1942 b$ ), in the special case of the lethal gene Curly. The problem was then nearly completely abandoned until Prout's articles (1965, 1969, 1971 $a$ and 1971b) followed by those of Anderson (1969) and Bundgaard and Christiansen (1972). To-day, some analyses of fitness components are available, which concern egg-to-adult viability and male sexual selection, whose relative importance depends upon the strains involved.

Maintenance of lethal genes being specially paradoxical, a new insight into the question might be of interest. Teissier's model was a good one and we decided to reconsider it. We thus undertook: (a) to analyse more precisely the fitness components, including sexual selection, considered today as an important component of fitness (for a review, see Petit and Ehrman, 1969; Spiess, 1970), (b) to determine the relative importance of heterosis, as demonstrated by Teissier, and also frequency-dependent selection, which was suspected by L'Heritier and Teissier $(1934,1937)$ in experimental populations, analysed by Petit $(1951,1954,1958)$ and demonstrated in sexual selection and viability (for a review, see Ayala and Campbell, 1974, Petit, 1974).

To be sure that Curly would not be eliminated, vestigial, whose poor viability is known, was chosen as a competitor.

* Equipe de recherche associée au Centre National de la Recherche Scientifique $n^{\circ} 406$ : Analyse et mécanismes de maintien du polymorphisme. 


\section{Material and Methods}

The balanced stock Curly Oster was used, being a very good suppressor of crossing over in chromosome 2. The vestigial stock had been kept for several years in the laboratory and was genetically homogeneous. The two strains were made isogenic for the rest of their genome, in order to prevent segregation effects for other loci; for this purpose, full-sib matings were performed for seven generations in fourteen lines as follows (female first):

$$
\begin{array}{r}
\text { Generation } 0: \frac{C y 0}{33 K_{P m l}} \times \frac{+v g}{+v g} \\
\text { Generation } 1: \frac{C y 0+}{+v g} \times \frac{C y 0+}{+v g} \\
\mathrm{G}_{2} \text { to } \mathrm{G}_{7}: \frac{C y 0+}{+v g} \times \frac{+v g}{+v g} .
\end{array}
$$

Some lines were lost during inbreeding, but only one of each type was needed. The two strains $C y(C y 0+/+v g)$ and $v g(+v g /+v g)$ were highly inbred, except for chromosome II, which was protected from recombination by the pericentric inversion of $C y 0$.

\section{(i) The populations}

Four populations were maintained by serial transfer in half-pint milk bottles on $\mathrm{S} 101$ food medium enriched by fresh yeast. In populations $\mathrm{H}_{4}$ and $\mathrm{H}_{2}$, the initial phenotypic frequency of $C y$ was 1 ; in populations $\mathrm{L}_{3}$ and $\mathrm{L}_{4}$, the frequency was $0 \cdot 10$. They were kept at $25^{\circ} \mathrm{C}, 80$ per cent $\mathrm{RH}$ and a photoperiod of 12 hours at 1000 lux. Competition for food occurred among the larvae. Evolution was followed for 23 discrete generations. For each generation, flies of the $n$th generation hatched during the three days following the first emergence, were placed for a 24 hour-period in a fresh medium bottle, their eggs constituing generation $n+1$. The parents were then counted to evaluate the composition of the $n$th generation.

\section{(ii) Fertility}

Five day-old mated females were permitted to lay eggs for two hours on histological plates covered by charcoal blackened S101 medium. Some 22-30 hours later, the number of unhatched eggs were counted and the proportion of hatched eggs estimated.

\section{(iii) Larvo-pupal viability}

Different ratios of $C y$ and $v g$ flies were allowed to lay eggs. For each of them, one group of 150 first instar larvae were placed on a rich food medium to reduce larval competition (uncrowded series: UCS); they provided a sample of adults developed from the first stage larvae. Another group of 150 larvae were placed on a poor medium, so that larval competition was about the same as in the population bottles (crowded series: CS). The difference of frequencies between the two series was due to larval competition. Several runs were made at each frequency. 


\section{(iv) Female fecundity}

The number of eggs laid from 1-12 days was measured for the different mating types. One female and two males, all newly hatched, were placed in a vial with maize medium and fresh yeast. They were transferred every two days into a new vial. Females that died were not replaced, but males were. Differences in means were tested by the Mann-Whitney $U$ nonparametric test, since fecundity is not distributed normally.

\section{(v) Sexual selection}

The influence of female genotype was studied in 4 day-old virgin males and females. 12 males and 12 females of each genotype were put into an Elens-Wattiaux chamber (1964) and observed for $2 \frac{1}{2}$ hours; the type and time of occurrence of every mating was recorded. To have a better evaluation of sexual selection in the bottles, the multiple choice technique was used: 1003 day-old virgin $C y$ and $v g$ males, in different phenotypic proportions, were put together with 100 virgin vg females. 24 hours later, the females were placed in individual vials. The male type they mated with was inferred from the progeny. $C y$ females were not used, since their progeny from the two mating types differs only in $C y$ frequency, making the analysis doubtful and time-consuming.

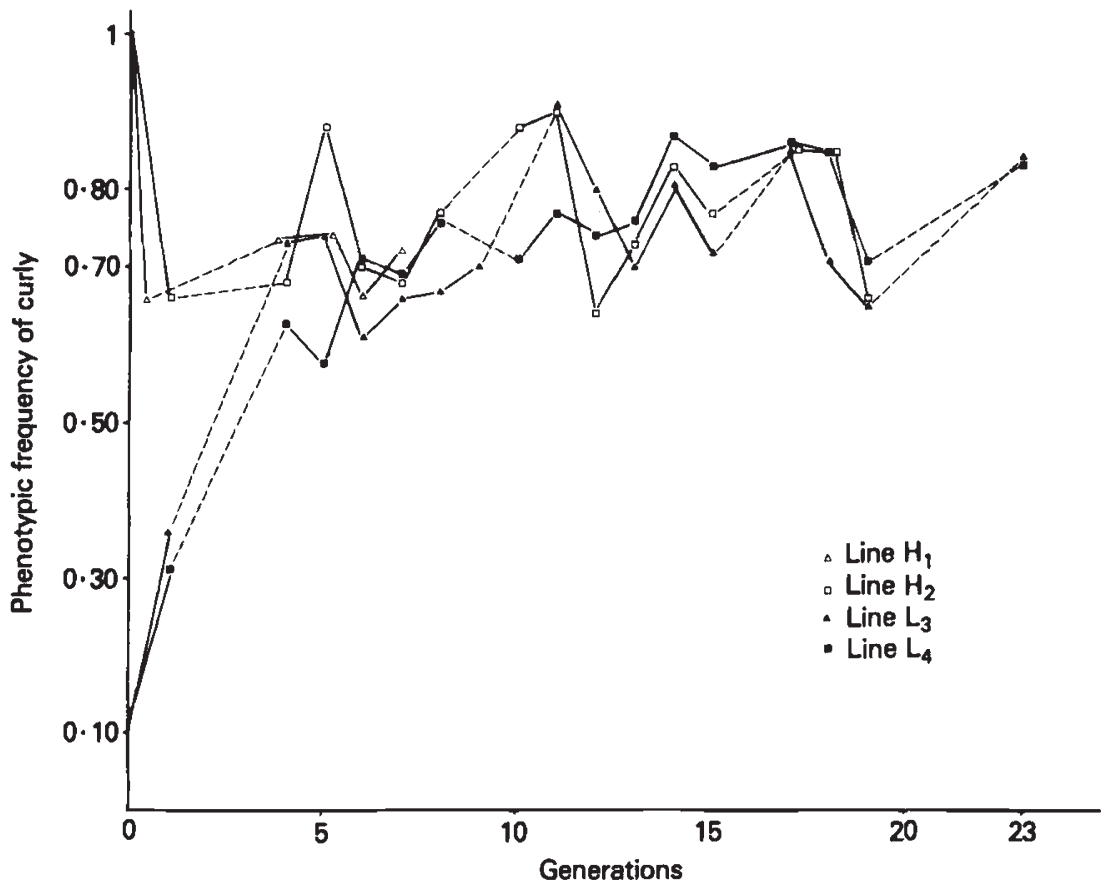

FIG. 1. Evolution of Curly phenotypic frequencies in the experimental populations. 


\section{Results}

\section{(i) Evolution of experimental populations}

Fig. 1 presents the evolution of phenotypic frequencies in the cages. The two $H$ populations were stopped at the 7 th and 20th generations respectively because of the occurrence of a recombination between $C y$ and vg. One of the $H$ populations and the two $L$, each about 400 individuals, reached a genetic equilibrium about the 4 th generation. This quick approach, explained by lethality in the $\mathrm{H}$ populations (Teissier, 1944), suggests frequency-dependent selection in one or several components of fitness in the low ones. The equilibrium frequencies, calculated from the 4 th generation on, were very similar and averaged $0.75 \pm 0.003 C y$ phenotypes (table 1).

\section{TABLE 1}

Average phenotypic frequencies of $\mathrm{Cy}$ at equilibrium (calculated from the 4 th generation to generation 19 or 23 )

\begin{tabular}{ccc}
\hline $\begin{array}{c}\text { Line } \\
\text { (to generation) }\end{array}$ & $\begin{array}{c}\text { Phenotypic frequency } \\
\text { of } C y\end{array}$ & $\begin{array}{c}\text { Theoretical phenotypic } \\
\text { frequency }\end{array}$ \\
\hline$H_{2}\left(\rightarrow G_{19}\right)$ & $0.767 \pm 0.005$ & 0.10 \\
$L_{3}\left(\rightarrow G_{23}\right)$ & $0.755 \pm 0.005$ & 0.04 \\
$L_{4}\left(\rightarrow G_{24}\right)$ & $0.737 \pm 0.005$ & 0.04 \\
All & $0.753 \pm 0.003$ & - \\
\hline
\end{tabular}

These results might be compared to the theoretical evolution of a population in which $C y$ would be completely lethal when homozygous, and the adaptive values of $C y$ and $v g$ phenotypes identical, that is $\sigma_{1}=0, \sigma_{2}=\sigma_{3}$. Let $n$ be the generation number, $q_{0}$ and $p_{0}$ the initial allelic frequencies of $C y$ and $v g, q_{n}=q_{0} /\left(1+n q_{0}\right)$. In $\mathrm{H}_{2}, q_{0}=0.50$, then $q_{n}=0.05 ;$ in $\mathrm{L}_{3}$ and $\mathrm{L}_{4}$, $q_{0}=0.05$, then $q_{n}=0.02$. The differences between observed and theoretical frequencies (table 1) demonstrate that the above hypothesis is false, a conclusion first obtained by Teissier.

TABLE 2

Egg fertility of $\mathrm{Cy}$ and $\mathrm{vg}$ phenotypes depending upon the mating type in Drosophila melanogaster

\begin{tabular}{|c|c|c|c|c|c|c|}
\hline $\begin{array}{l}\text { Mating } \\
\text { number }\end{array}$ & $\begin{array}{c}\text { Mating } \\
\text { type* }\end{array}$ & $\begin{array}{l}\text { Eggs } \\
\text { laid }\end{array}$ & $\begin{array}{c}\text { Eggs } \\
\text { hatched }\end{array}$ & $\begin{array}{l}\text { Eggs not } \\
\text { hatched }\end{array}$ & $x^{2}$ & Hatched \% \\
\hline 1 & $C y \times C y$ & 305 & 234 & 71 & & $76 \cdot 7 \pm 1 \cdot 7$ \\
\hline $2 c$ & $C y \times v g$ & 365 & 324 & 41 & & $88 \cdot 8 \pm 1 \cdot 7$ \\
\hline $2 v$ & $v g \times C y$ & 131 & 118 & 13 & & $90 \cdot 1 \pm 2 \cdot 6$ \\
\hline $2 c+2 v$ & & 496 & 442 & 54 & & $89 \cdot 1 \pm 1 \cdot 4$ \\
\hline 3 & $v g \times v g$ & 831 & 697 & 134 & & $84 \cdot 0 \pm 1 \cdot 3$ \\
\hline \multicolumn{7}{|l|}{ Comparison } \\
\hline $2 c \vee 2 v$ & & & & & 0.21 & \\
\hline $1 \vee v(2 c+2 v)$ & & & & & $22 \cdot 27$ ** & \\
\hline $3 \vee(2 c+2 v)$ & & & & & $7 \cdot 00^{\text {*** }}$ & \\
\hline
\end{tabular}

* Female first.

** significant at the 0.01 level. 


\section{(ii) Egg fertility and embryonic mortality}

The results (table 2 ) demonstrate that, in mixed matings (mating types $2 c$ and $2 v$ ), the mother's genotype had no influence on hatching percentage. The results for $2 c$ and $2 v$ could thus be combined, and compared with the $C y \times C y$ and the $v g \times v g$ matings. Both with $C y$ and $v g$ the differences were highly significant, with eggs from the mixed matings having a higher fertility than that of homogametic matings: $89 \cdot 1>84 \cdot 0>76 \cdot 7$.

It was difficult to give a direct evaluation of the egg viability for each genotype, as $C y$ 's lethality seems to depend on the strain used (Kuroda and Minato, 1976). An indirect estimate could be made by combining the results from different cross types, using the simple mendelian expectations (equations in table 3 ). Solving these equations gives $x_{1}=0.36 ; x_{2}=0.94$; $x_{3}=0 \cdot 84$. These demonstrate: (a) heterosis in embryo fertility; (b) only a partial lethality of $C y+/ C y+$ genotypes in the embryonic stage.

TABLE 3

Evaluation of the egg fertility coefficients. $\left(\mathrm{x}_{1}, \mathrm{x}_{2}, \mathrm{x}_{3}\right.$ represent the fertility of $\mathrm{Cy}+/ \mathrm{Cy}+, \mathrm{Cy}+/ \mathrm{vg}$ and $+\mathrm{vg} / \mathrm{vg})$

\begin{tabular}{cl}
\hline $\begin{array}{c}\text { Experiment } \\
\text { number }\end{array}$ & Mating types \\
\hline 1 & $C y \times C y \rightarrow 0.25 x_{2}+0.25 x_{3}=0.77$ \\
$2 c$ & $C y \times v g \rightarrow 0.50 x_{2}+0.50 x_{3}=0.89$ \\
$2 v$ & $v g \times C y \rightarrow 0.50 x_{2}+0.50 x_{3}=0.90$ \\
3 & $v g \times v g \rightarrow x_{3}=0.84$ \\
& Estimates \\
& $x_{3}=0.84$ \\
& $x_{2}=0.94$ \\
& $x_{1}=0.36$ \\
\hline
\end{tabular}

(iii) Larvo-pupal viability in competitive competition

Larvo-pupal viability of $C y$ homozygote had first to be tested. To check on this, $150 C y$ females were mated individually with $v g$ males. If $C y$ were lethal in the larvo-pupal stage, all adults phenotypically $C y$ would be heterozygous $C y+/+v g$; a female of this genotype mated with a $v g$ male would produce about 50 per cent of vestigial flies. If it were only sublethal, some of the $150 C y$ females would be $C y+/ C y+$ and, mated with $v g$ males, would produce $C y+/+v g$ progeny. However, vg appeared in the progeny of the all females, which demonstrated that all phenotypically $C y$ females were $C y+/+v g$ and $C y+/ C y+$ was really lethal in our strain; its larvopupal viability was zero.

Larvo-pupal viability of heterozygous and vestigial genotypes was estimated by the ratio of the frequencies of adult genotypes emerging in the crowded (CS) and in the uncrowded (UCS) series. Let $r$ and $1-r$ the observed frequency of the $C y$ and $v g$ phenotypes among the UCS series, $R$ and $1-R$, the corresponding frequencies among the CS series. Viabilities of the genotypes are as follows: 


$$
\begin{aligned}
& y_{1}(C y+/ C y+)=0 \\
& y_{2}(C y+/+v g)=\frac{R}{r} \\
& y_{3}(+v g /+v g)=\frac{1-R}{1-r} .
\end{aligned}
$$
is:

Then, the relative viability of $C y$ heterozygotes versus $v g$ homozygotes

$$
Y=\frac{R}{r}: \frac{1-R}{1-r} .
$$

The standard error on this coefficient is $Y \sqrt{1 / N R(1-R)}$ (Petit, 1958), $N$ being the number of emerged adults in the crowded series.

Several frequencies of $C y$ were tested, viability being often frequencydependent (Petit, 1966; Kojima and Yarbrough, 1967; Ayala and Campbell, 1974; Anxolabehere, 1976; Palabost, 1980). The results of the different runs of each frequency being statistically homogeneous, they have been pooled (table 4). Whatever the frequencies, $C y$ are at a disadvantage.

Occurrence of frequency-dependence has been tested by means of a ratio diagram, Fig. 2 (Ayala, 1972). This diagram uses the ratio between

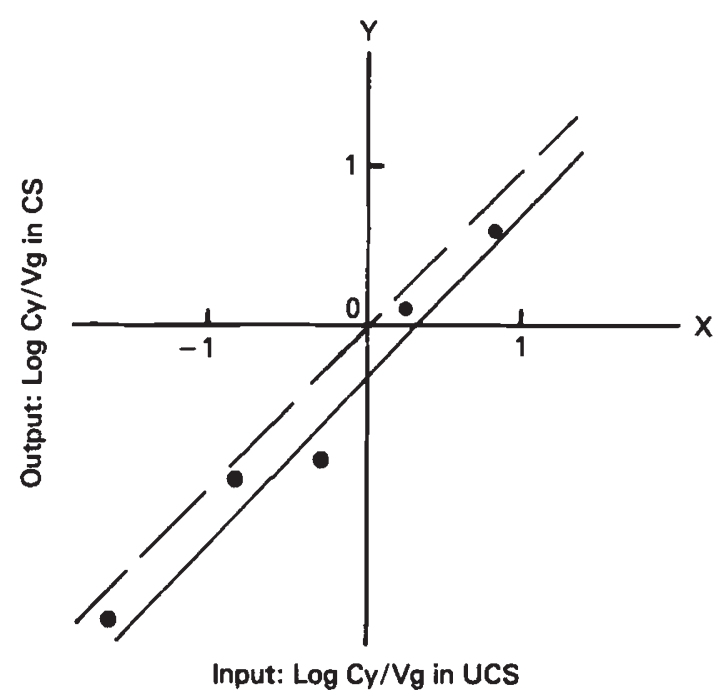

FIG. 2. Larvo-pupal viability: Ratio diagram for the regression of the output frequencies (log.

$C y / v g$ in crowded series); on the input frequencies (log. $C y / v g$ in uncrowded series).

the two genotypes and plots the logarithm of the output (number of flies emerged from the crowded series) in the ordinate versus the logarithm of the input (number of flies emerged from the uncrowded ones) ratios in abscissa. The equation of the regression line is: $y=1.02 \times-0.30$. Its slope was tested against unity by a $t$-test. The standard-error is 0.10 and $t$ equals $0 \cdot 20$. So the slope of the regression line is not significantly different from unity, which suggests no frequency-dependence. The location of the 


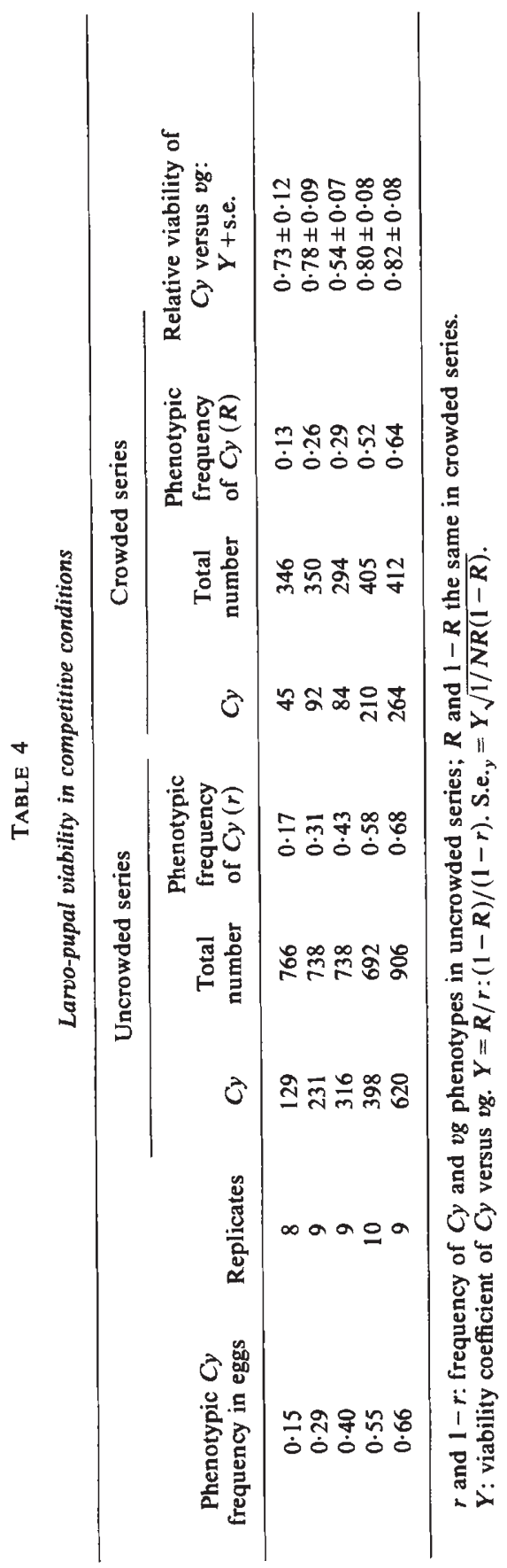


regression line under the diagonal demonstrates that $C y$ is at a disadvantage, which confirms results obtained by $Y$ coefficient. The mean value of $Y$ is 0.74 .

Next, viability from egg to adult can be calculated combining fertility and larvo-pupal viability. Relative to $v g, C y$ fertility and larvo-pupal viability being $1 \cdot 12(0.94: 0.84)$ and $0.73, C y$ versus $v g$ viability from egg to adult equals $0 \cdot 82$. This result differs from Teissier's, who demonstrated heterosis. The causes of this difference will be discussed in the general conclusion.

\section{(iv) Female fecundity}

Female fecundity has been evaluated: (a) during the first 4 days, to reproduce the population's conditions, where parents of every generation were killed on the 4th day following emergence, (b) during the 10 or 12 first days' to evaluate the potential fecundity (table 5). The evaluation during the first 4 days demonstrates that mixed crosses $C y \times v g(2 c)$ and $v g \times C y(2 v)$ have the same fecundity. Both homogamic genotypes have a lower fecundity, with a bigger disadvantage for $v g$ than for $C y$, in spite of $C y$ lethality; this probably ensues from facilitation phenomena (Lewontin 1955) which occur when $C y$ and $v g$ develop in the same medium.

TABLE 5

Fecundity during the first 4 days and the first 10 days for four mating types

\begin{tabular}{|c|c|c|c|c|c|c|c|}
\hline \multirow{2}{*}{$\begin{array}{l}\text { Mating } \\
\text { type }\end{array}$} & \multirow{2}{*}{$\begin{array}{l}\text { Mating type } \\
\text { phenotypes } \\
\$ \delta\end{array}$} & \multirow{2}{*}{ Number } & \multirow{2}{*}{$\begin{array}{l}\text { Average } \\
\text { fecundity } \\
\text { ( } 4 \text { days). }\end{array}$} & \multirow{2}{*}{$\begin{array}{c}\text { Fecundity } \\
\text { versus } \\
v g \times v g\end{array}$} & \multirow{2}{*}{$\begin{array}{l}\text { Average } \\
\text { fecundity } \\
\text { (10 days })\end{array}$} & \multicolumn{2}{|c|}{$\begin{array}{c}\text { Mann- } \\
\text { Whitney } U\end{array}$} \\
\hline & & & & & & 4 days & 10 days \\
\hline 1 & $C y \times C y$ & 25 & 66 & $1 \cdot 37$ & 214 & & \\
\hline $2 c$ & $C y \times v g$ & 20 & 101 & $2 \cdot 20$ & 271 & & \\
\hline $2 v$ & $v g \times C y$ & 24 & 111 & $2 \cdot 20$ & 217 & & \\
\hline 3 & $v g \times v g$ & 12 & 48 & 1.00 & 141 & & \\
\hline \multicolumn{8}{|c|}{ Comparison } \\
\hline $1 v 2 c$ & & & & & & $2 \cdot 63^{* *}$ & $2 \cdot 44^{*}$ \\
\hline $2 c v 2 v$ & & & & & & 0.83 & $2 \cdot 03^{*}$ \\
\hline $2 v v 3$ & & & & & & $3 \cdot 96^{* *}$ & $2 \cdot 38^{* *}$ \\
\hline $1 v 3$ & & & & & & $1 \cdot 30$ & $2 \cdot 89^{* *}$ \\
\hline
\end{tabular}

* Significant at the 0.05 level.

** Significant at the 0.01 revel.

Given the technique used, these results in fact include not only fecundity, but also premating time, developmental time and $C y$ homozygote viability.

To reduce the effect of premating and developmental time, fecundity has been evaluated during the first 10 days of adult life (table 5). Mixed crosses $(2 c$ and $2 v$ ) then have a different fecundity depending upon the mother's phenotype. Crosses between both males and females vg (3) have a much lower fecundity. This table does not seem to demonstrate any influence of female phenotype on fecundity. However two points have been neglected: (a) the $C y$ homozygotes disappear in the progeny of $C y \times C y$. Thus the mean egg production of this type of cross (neglecting egg to adult 
viability) would be $214 \times 4 / 3=285$ eggs; which is not statistically different from 271 eggs, obtained from $C y \times v g$, (b) in the crosses $v g \times v g$, females begin to lay eggs on the third day instead of on the first for the other crosses (unpublished data). The fertility of the first 10 days of laying is then that of the first 12 days and equals 210 , quite near the value of 217 , for the $2 v$ mating type. Thus, fecundity sensu stricto depends on female phenotype, and $C y$ females are heterotic. Nevertheless this heterosis is reduced in populations by $C y+/ C y+$ lethality and differences in premating time.

The actual fertility results (4th column in table 5) have to be taken into account in the evolution of the populations.

\section{(v) Sexual selection}

Comparisons with random mating and influences of male or female genotypes were tested by means of a chi-square for goodness-of-fit to a random mating distribution. The frequency-dependent mating success was measured by $K$, Petit's coefficient. $S$ and $1-S$ being the ratio of females mated with $C y$ and $v g$ males, $s$ and $1-s$ the ratio of $C y$ and $v g$ males, $N$, the number of mated females, $K=S / s:(1-S) /(1-s)$. The standard error on this coefficient is $e_{K}=K \sqrt{1 / N S(1-S)}$ (Petit, 1958). Taking into account the number of matings $(N=274)$, the bias on this coefficient (Goux and Anxolabehere, 1980, Anxolabehere et al., 1982) is negligible.

The results obtained in Elens-Wattiaux chambers from intermating of $636 C y$ and $636 v g$ pairs are given in table 6, and demonstrate a discrepancy

TABLE 6

Sexual selection between $\mathrm{Cy}$ and vg males studied in ElensWattiaux chambers (Cy phenotypic frequency: 0.50)

\begin{tabular}{|c|c|c|c|}
\hline & \multicolumn{2}{|c|}{ Number of matings } & \multirow[b]{2}{*}{ Total } \\
\hline & $C y q q$ & vg & \\
\hline$C y$ ठेठ & 233 & 188 & 421 \\
\hline vg $0 \sigma^{\circ}$ & 47 & 69 & 116 \\
\hline Total & 280 & 257 & 537 \\
\hline \multicolumn{4}{|c|}{ 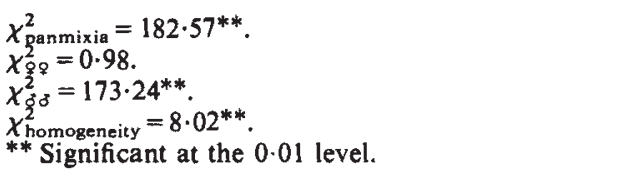 } \\
\hline
\end{tabular}

from a panmictic distribution $\left(\chi^{2}=182 \cdot 57\right)$. It is due to a male selection in favor of $C y$ males $\left(\chi_{\delta}^{2}=173.24\right.$ for $\left.1 \mathrm{df}\right)$, and not to any female selection $\left(\chi_{q}^{2}=0.98\right.$ for $\left.1 \mathrm{df}\right)$; in fact, the ratio of $C y$ and $v g$ females mated either with $C y$ or with $v g$ males are not homogeneous $\left(\chi^{2}=8.02\right.$, significant at the 0.01 level), which demonstrates a tendency to homogamic mating.

The results of multiple choice experiments, performed with $3220 \mathrm{vg}$ females, with 2879 mated, (table 7) demonstrate a very strong frequencydependent advantage of the heterozygous males (fig. 3). The quadratic regression curve is: $K=44 \cdot 01 s^{2}-31 \cdot 59 s+6 \cdot 84$. 
TABLE 7

Sexual selection between Cy and vg males, measured by the technique of multiple choice, and evaluated by Petit's $K$ coefficient

\begin{tabular}{|c|c|c|c|c|c|c|}
\hline \multirow{2}{*}{$\begin{array}{l}\text { Phenotypic } \\
\text { frequency } \\
\text { of } C y(\mathrm{~s})\end{array}$} & \multicolumn{2}{|c|}{ Males } & \multicolumn{2}{|c|}{$\$ \subsetneq$ mated with $\delta \delta$} & \multirow{2}{*}{$\underset{\text { panmixia }}{\chi^{2}}$} & \multirow{2}{*}{$\begin{array}{l}\text { Sexual selection } \\
\text { coefficient of } \delta \delta \\
\text { followed by its S.e. }\end{array}$} \\
\hline & $C y$ & $v g$ & $C y$ & $v g$ & & \\
\hline 0.10 & 40 & 349 & 149 & 232 & $336 \cdot 25^{* *}$ & $5.6^{*} \pm 0.59$ \\
\hline 0.20 & 160 & 632 & 340 & 358 & $321 \cdot 29 * *$ & $3.75^{*} \pm 0.28$ \\
\hline 0.39 & 230 & 357 & 295 & 209 & $79 \cdot 73^{* *}$ & $2 \cdot 19^{*} \pm 0.20$ \\
\hline 0.60 & 354 & 232 & 342 & 184 & $10 \cdot 34^{*}$ & $1 \cdot 22^{*} \pm 0 \cdot 11$ \\
\hline 0.80 & 455 & 113 & 423 & 73 & $16 \cdot 41^{* *}$ & $1.44^{*} \pm 0.18$ \\
\hline 0.90 & 266 & 31 & 248 & 26 & $2 \cdot 02$ & $1 \cdot 11 \pm 0.23$ \\
\hline
\end{tabular}

$K=S / s:(1-S) /(1-s)$.

S.e. ${ }_{k}=K \sqrt{1 / N S(1-S)}$.

$s$ and $1-s$ : phenotypic frequencies of $C y$ and $v g$ males.

$S$ and $1-S$ : phenotypic frequencies of females mated with $C y$ or $v g$ males.

$N$ : total number of mated females.

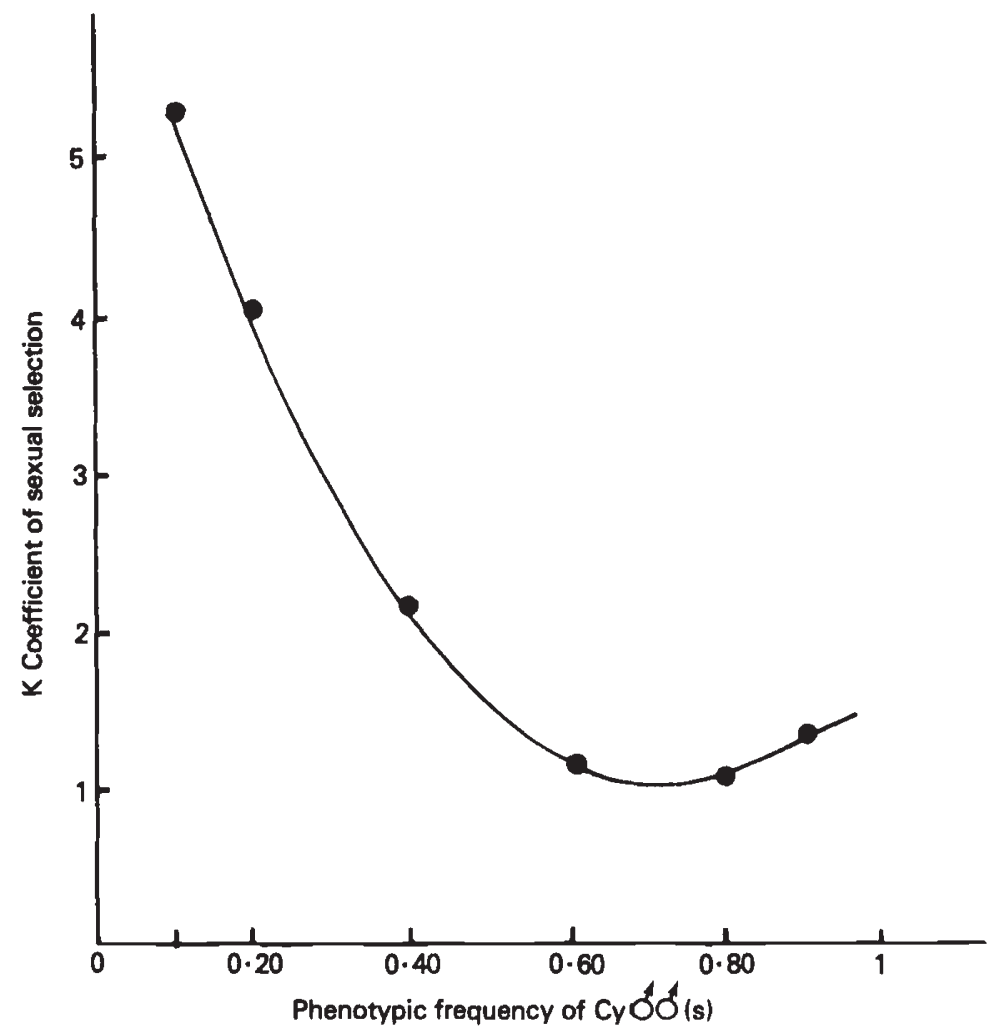

FIG. 3. Sexual selection: variation of Petit's K coefficient of sexual selection as a function of $C y$ phenotypic frequency. Experimental points. 
Though not ambiguous, frequency-dependence has been tested by a ratio diagram where the output represents the logarithm of the ratio of females mated with $C y$ and $v g$ males, and the input, the logarithm of the ratio of $C y$ and $v g$ males in the population. The equation of the regression line (fig. 4) is: $y=0.63 x+0.75$. The standard error on the slope is 0.05 . The comparison with the diagonal ( $t=7 \cdot 4$ for $5 \mathrm{fd}$ ) is highly significant.

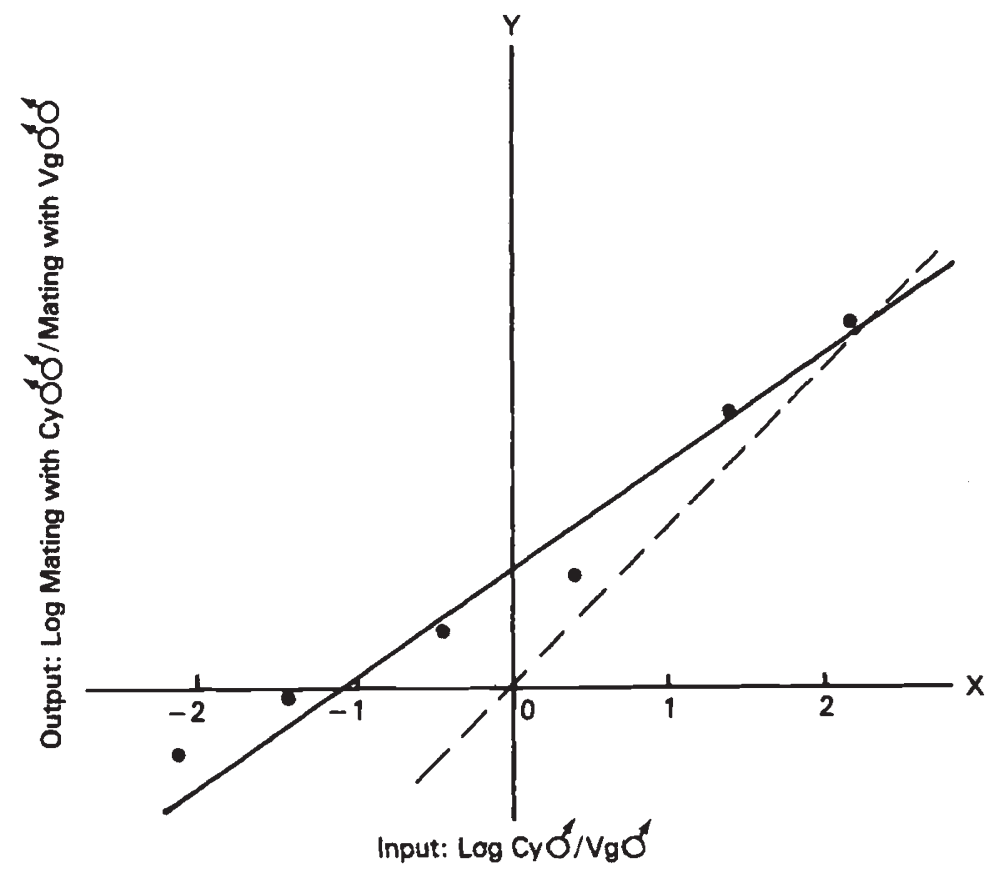

FIG. 4. Sexual selection: Ratio-diagram for the regression of the output ratio (log matings with $C y$ males/matings with $v g$ males) to the input ratio (log $C y$ males/vg males).

A comparison of the results obtained by the two techniques had to be made. With $0.50 C y$ males, $K=4.76 \pm 0.79$ for $C y$ females, $2.77 \pm 0.38$ for $v g$ females, in Elens-Wattiaux chambers (table 7) and $K=1 \cdot 50 \pm 0 \cdot 15$ for $v g$ females in multiple matings (fig. 3 ).

Thus, the selection coefficient of $C y$ versus vg males measured in Elens-Wattiaux chambers is twice the coefficient obtained by the multiple matings technique available from the type of experimentation practised so far. It may be due to the different physical environment of the two procedures, or to the presence of one or two female genotypes resulting in complex interactions. New experiments will be necessary to answer the question.

In any case, a strong frequency-dependent sexual selection has been demonstrated in conditions very similar to the conditions of the experimental populations.

\section{Discussion and Conclusion}

The three populations, followed for at least 20 generations, attained a balanced polymorphism by the 4 th generation. The level of equilibrium, 
very similar in the three, was $0.75 \pm 0.003 C y$ phenotypes (instead of 0.66 in Teissier's experiments). The fluctuations around the equilibrium were usually parallel, which might be explained by the isogenicity of the competing strains which removes all recombinational variability. Their polymorphism seems to be maintained by a balance between: (1) $C y$ lethality and smaller egg-to-adult viability of $C y$ heterozygotes, (2) higher fecundity of crosses in which one (or both) parents are heterozygous, (3) a high frequency-dependent sexual selection in favor of $C y$ heterozygous males with advantage of the rare type. In Teissier's model, $C y$ 's lethality was balanced by a higher viability and fecundity of $C y$ heterozygotes, and the equilibrium value was 0.66 .

Some of these differences might be explained by the different genetic backgrounds and different intensities in the competition for food. More puzzling is the fact that his model, in which sexual selection was neglected, fits well to the equilibrium value obtained experimentally, while sexual selection, clearly demonstrated in our strains, had every chance of interfering. Frequency-dependent selection can be responsible for the discrepancy. Teissier's populations, initiated with 100 per cent $C y$ attained a level of equilibrium of 0.66 . Now, for these frequencies, the coefficient of sexual selection is about 1 and might be neglected, the quick fall to equilibrium being mainly due to $C y$ lethality, an explanation that fits our $\mathrm{H}_{2}$ population. On the contrary, in our populations initiated with $0 \cdot 10 C y$, sexual selection is important during evolution to equilibrium; the sexual selection coefficient varies from 5 to 1 while $C y$ phenotypic frequency rises from $0 \cdot 10$ to $0 \cdot 60$. When the populations are in equilibrium, sexual selection is no longer efficient and the polymorphism is maintained essentially by viability and fecundity.

These conclusions might be tested by a model. But the model built with our sexual selection coefficient would be biased as sexual selection was under-estimated in our experiments and will need new evaluations.

This series of experiments and its comparison with Teissier's results demonstrate that the role which each major component of fitness is expected to play in experimental populations changes as the gene frequency changes, and is consequently different in stable or evolving populations. This result, demonstrated by Bundgaard and Christiansen (1972) in the dynamics of a fourth chromosome polymorphism in Drosophila melanogaster, and by Anxolabehere (1980) in the competition at the sepia locus, must be found every time that the evolution of one of the components of fitness is controlled by frequency-dependent selection.

Acknowledgments. We are grateful to Doctors C. Krimbas, D. Anxolabehere, M. Katz and the unknown referee for their comments and suggestions. Dr A. Kovoor was very helpful in supervising the translation of the introduction and conclusion.

\section{REFERENCES}

ANDERSON, W. W. 1969. Selection in experimental populations. I: Lethal genes. Genetics, 62, 653-672.

ANXOLABEHERE, D. 1976. Heterosis, overdominance and frequency-dependent selection in Drosophila melanogaster at the sepia locus. Evolution, 30, 523-534.

ANXOLABEHERE, D. 1980. The influence of sexual and larval selection on the maintenance of polymorphism at the sepia locus in Drosophila melanogaster. Genetics, 71, 439-460. 
ANXOlABEHERE, D., GOUX, J. M. AND PERIQUet, G. 1982. A bias in estimation of viabilities from competition experiments. Heredity, 48, 271-282.

AYALA, F. J. 1972. Frequency-dependent mating advantage in Drosophila. Behav. Genet., 2, 85-91.

AYAla, F. J. AND CAMPBEll, C. A. 1974. Frequency dependent selection. Ann. Rev. Ecol. Syst., $5,115-138$

BUNDGAARD, J. AND CHRISTIANSEN, F. B. 1972. Dynamics of polymorphism: I. Selection components in an experimental population of Drosophila melangaster. Genetics, 71,439 460.

ElENS, A. A. AND wattiauX, J. M. 1964. Direct observation of sexual isolation. D.I.S., 39, 118-119.

GOUX, J. M. AND ANXOLABEHERE, D. 1980. The measurement of sexual isolation and selection: a critique. Heredity, $45,255-262$.

KOJIMA, K. I. AND YARBROUGH, K. M. 1967. Frequency-dependent selection at the Esterase-6 locus in Drosophila melangaster. Proc. Nat. Acad. Sci. USA, 57, 645-649.

KURODA, Y. AND MINOTA, K. 1976. Effective lethal phase of the $C y$ mutant in Drosophila melanogaster. An. Rep. Nat. Inst. Genet. Japan, 26, 31-32.

LEWONTIN, R.C. 1955. The effects of population density and composition on variability in Drosophila melangaster. Evolution, 9, 27-41.

L'HERITIER, PH. AND TEISSIER, G. 1934. Une expérience de sélection naturelle. Courbe d'élimination du gène Bar dans une population de Drosophila melanogaster. C.R. Soc. Biol, 117, 1049.

L'HERITIER, PH. AND TEISSIER, G. 1937. Elimination des formes mutantes dans les populations de Drosophila. C.R. Soc. Biol. 117, 880-884.

PALABOST, L. 1980. The maintenance mechanism of polymorphism at the $\alpha$-Gpdh locus in Drosophila melanogaster. Bioch. Genetics 18, 905-915.

PETIT, C. 1951. Le rôle de l'isolement sexuel dans l'évolution des populations de Drosophila melanogaster. Bull. Biol. France Belgique, 85, 392-418.

PETIT, C. 1954. L'isolement sexuel chez Drosophila melanogaster. Etude du mutant $w$ et de son allélomorphe sauvage. Bull. Biol., 88, 435-443.

PETIT, C. 1958. Le déterminisme génétique et psychophysiologique de la compétition sexuelle chez Drosophila melanogaster. Bull. Biol. 92, 248-329.

PETIT, C. 1966. La concurrence larvaire et le maintien du polymorphisme. C.R. Acad. Sc. Paris, 263, 1262-1265.

PetIT, C. 1974. L'avantage du type rare, facteur de maintien du polymorphisme. Mémoires Soc. Zool. France, 37, 417-441.

PETIT, C. AND EHRMAN, L. 1969. Sexual selection in Drosophila. Evolutionary Biology, 3. (ed.) Dobzhansky, Hecht and Steere, pp. 177-223.

PROUT, T. 1965. The estimation of fitness from genotypic frequencies. Evolution, 19, 546-551. PROUT, T. 1969. The estimation of fitness from population data. Genetics, 63, 949-967.

PROUT, T. $1971 \mathrm{a}$. The relation between fitness components and population prediction in Drosophila. I. The estimation of fitness components. Genetics, 68, $127-149$.

PROUT, T. $1971 \mathrm{~b}$. The relation between fitness components and population prediction in Drosophila. II. Population prediction. Genetics, 68, 151-167.

SPIESS, E. 1970. Mating propensity and its genetic basis in Drosophila. Evolutionary Biology. (Supplement) (ed.) Hecht and Steere, pp. 316-379.

TElssier, G. 1942a. Persistance d'un gène lethal dans une population de Drosophiles. C.R. Acad. Sci, 214, 327-330.

TEISSIER, G. $1942 b$. Vitalité et fécondité relatives de diverses combinaisons génétiques comportant un gène léthal, chez la Drosophile. C.R., Acad. Sci., 214, 241-244.

TEISSIER, G. 1944. Equilibre des gènes léthaux dans les populations stationnaires panmictiques. Revue scientifique. 3230-3231, 145-159. 